\title{
Core Banking System Scalability Review
}

\author{
Achmad Fakhrudin ${ }^{1}$, Heru P Ipung ${ }^{1 *}$, M Amin Soetomo ${ }^{1}$ and Charles Lim ${ }^{1}$ \\ ${ }^{1}$ Department of Information Technology, Swiss German University, Tangerang \\ 15143 , Indonesia \\ * Corresponding author, email: heru.ipung@sgu.ac.id
}

\begin{abstract}
In carrying out the digital transformation, bank has to find their optimal routes to exploit the Open Banking opportunity and minimize or manage any threat. However open Banking models will be making implication on the increasingly hit from the external parties. It will be new and more unpredictable data volumes as third parties request access to the banking system. Bank has to prepare their Banking system on the Enterprise Architecture, and one of the concerns is on the scalability. For the traditional core banking system, the platform of mainframe and other legacy technology could remain the bottleneck to agility and scalability. In this paper, scalability testing and analysis are carried out to verify whether the traditional banking core system running on the power platform can be scalable to support open banking strategy. The results found were that the core banking system could be scalable, but needed a lot of enhancement on the core banking application side, as well as capacity upgrading on the server side.
\end{abstract}

Keywords: Core Banking System, Scalability, Open Banking, Transaction Volume

\section{Introduction}

The disruption wave as because of the digital technology are happen in all industry now, including in the banking industry (Accenture, 2018). Some of the existing banks have begun to be affected by this digital change, but most of them already know about the changes that must be made. The digital transformation strategy in each bank can be different, especially related to the condition of the organization and its customers.

The emergence of a number of new players in the financial industry turned out to also change the pattern of services expected by customers while influencing the income they received. Existing banks must make fundamental changes, especially related to the way they operate. Their services must be ensured in very good performance including being able to quickly launch new digital innovation services.

Bank has to implement new digital initiatives including Open Banking. Open Banking is the shifting strategy from closed to open banking models (Deloitte Digital, 2017). Their banking system: data, banking product and other services functions are shared and open to other institutions and third parties with the main objective to generate the additional value.

However there are many implications after implementing Open Banking. The more integrated external parties will create more transaction volume. Bank has to prepare their Banking system on the Enterprise Architecture. It would be suddenly the number of Transaction become huge after any business deal and collaboration with third parties.

Discussing about enterprise architecture system, there are top three concerns: Scalability, Availability and Performance. These parameters are really strategic in determining the user experience in transactions and in long term relationship. It also directly impact to business regarding to online revenue, business growth, competitiveness and high business interest (Shailesh Kumar, 2015). For the traditional banks, the platform of mainframe and other legacy technology could remain the bottleneck to agility and scalability (MIT Technology Review Insight, 2018). Banks has to modernize IT for many years to ensure the open banking system readiness.

This paper focused on review traditional core banking system to support open banking system model. The new comprehensive methodology was created based on the previous references. It's used to test the scalability with the targeted business volume number. 


\section{Materials and Methods}

\subsection{Open Banking Implementation Challenges}

There are challenges in implementation of open banking and other digital initiative. In such country such as Indonesia, it requires an adequate level of internet infrastructure in order to adopt the technology and provide the necessary support for its usage and growth. The internet infrastructure with proper band with in Indonesia is not well distributed and yet to reach many area. Bank has to also strengthen the privacy and security of data transferred over the internet network. Cybercrimes and hacking is a big reality in online banking, and this cause to a decline in trust on bank digital activities (Varda Sardana, 2018). Open banking implementation also has the impact of the additional transaction coming to the banking system. Bank has to prepare their system in the enterprise web application system (Shailesh, 2015).

\subsection{Online Banking Performance Parameter}

The design of Web site and online banking resulting quick response time to the users should be provided by Banks. Bank customer would be more motivated to access the web system if they have the good performance especially on the response time. (Fida Hussain Chandio et all., 2017). Forrester, sponsored by Akamai Technologies (NASDAQ: AKAM) has conducted study at 2009. They released key findings at e-Commerce web site performance in correlation with behaviours of shopper. The result highlighted that the new threshold response time of web application expected by the user is in two seconds. They will abandon the online web commerce if they have to wait the response more than 3 seconds. That is the new expectation as the similar study conducted 3 years before resulted 4 seconds for the threshold.

The most variables affecting online banking customer satisfaction are: quick responsiveness, reliability of the system, efficient service, security, look and feel site (aesthetic), easy to use and user experience (Mohsen, 2015).

\subsection{Computer Performance}

Computer performance is majority determined by a combination of 2 parameters: first is throughput and the second is response time. The other aspects related with computer performance are computer power efficiency and systems availability (IBM, 2019). Computer system response time is the duration and elapsed time between the request of transactions submitted and the starting of a response to that transaction. At interactive users, the response time is the duration time to get the display result after clicking <enter> button. It's a critical aspect of performance as because of relation to the potential visibility of end users or customers. The computer system throughput is a measure of the number of work can be performed by a computer system at over the period of time.

Response time has the closely relation with throughput. As resources of computer (processors, disk, memory and etc) are used by many users and simultaneous transactions, it will result delays to individual transactions because of the similar resources are still uses by other transaction. The computer system resource that has the capability to in shared resource may cause additional response time because of the mechanism.

\subsection{Transaction Type}

There are 3 transaction types. The first is called I/O-limited transactions. It consists of a mix of considerable disk wait times. This transaction type will retrieve and get the most benefit from the good and an efficient of disk I/O subsystem (IBM, 2019). With the technology of disks, setting large disk cache, and also advance speed I/O links will do improve the throughput and response time and of these types of transactions. Application that has the characteristic on this transaction type is suggested to use SSDs as an alternative to previous technology of HDDs. 


\begin{tabular}{|c|c|c|c|c|c|c|c|c|}
\hline CPU Q & CPU & $\begin{array}{c}\text { Disk Read } \\
\text { Wait }\end{array}$ & CPU & $\begin{array}{c}\text { Disk Read } \\
\text { Wait }\end{array}$ & CPU Q & CPU & $\begin{array}{c}\text { Disk Read } \\
\text { Wait }\end{array}$ & Idle \\
\hline
\end{tabular}

Figure 1: I/O Limited transactions type

The second type of transaction is resource limited transaction. It consists of a considerable mix of processor and wait activity. These transactions type gain benefit most from improving application efficiency. To improve the system, application has to cut, minimize and reduce the impact of critical shared computer resources (between program applications and threads).

\begin{tabular}{|c|c|c|c|c|c|c|c|c|c|c|}
\hline $\begin{array}{c}\text { CPU } \\
Q\end{array}$ & CPU & $\begin{array}{c}\text { Soft Lock } \\
\text { Wait }\end{array}$ & CPU & $\begin{array}{c}\text { Soft Lock } \\
\text { Wait }\end{array}$ & CPU Q & CPU & $\begin{array}{c}\text { DB Lock } \\
\text { Wait }\end{array}$ & CPU Q & CPU & Idle \\
\hline
\end{tabular}

\section{Transaction}

Figure 2: Resource Limited transaction type

The third type is called processor-bound transactions. This type requires considerable processor cycles and very little I/O or wait times. The performance of the application with this type will be much better if they use higher processor frequency and also the efficiency of the processor pipeline stages. Utilizing of improved memory and processor will also generate better performance.

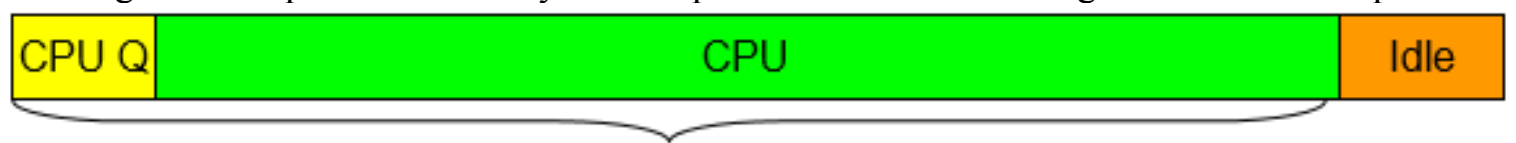

\section{Transaction}

Figure 3: Processor-bound transaction type

\subsection{System Scalability}

Scalability is related to the capability of system to manage and handle the additional demand and workload without neglecting the overall efficiency (Shailesh Kumar, 2015). This capability is mandatory for the enterprise application system and its related ecosystem. It has different elements related to scalability: Application and its ecosystem, increased workload and efficiency.

Figure 5 explain the scalability layers. It's informed based on order of contribution to scalability in the chain of request processing. This figure highlight that the layer of enterprise application give the major impact of the overall enterprise web application system. 


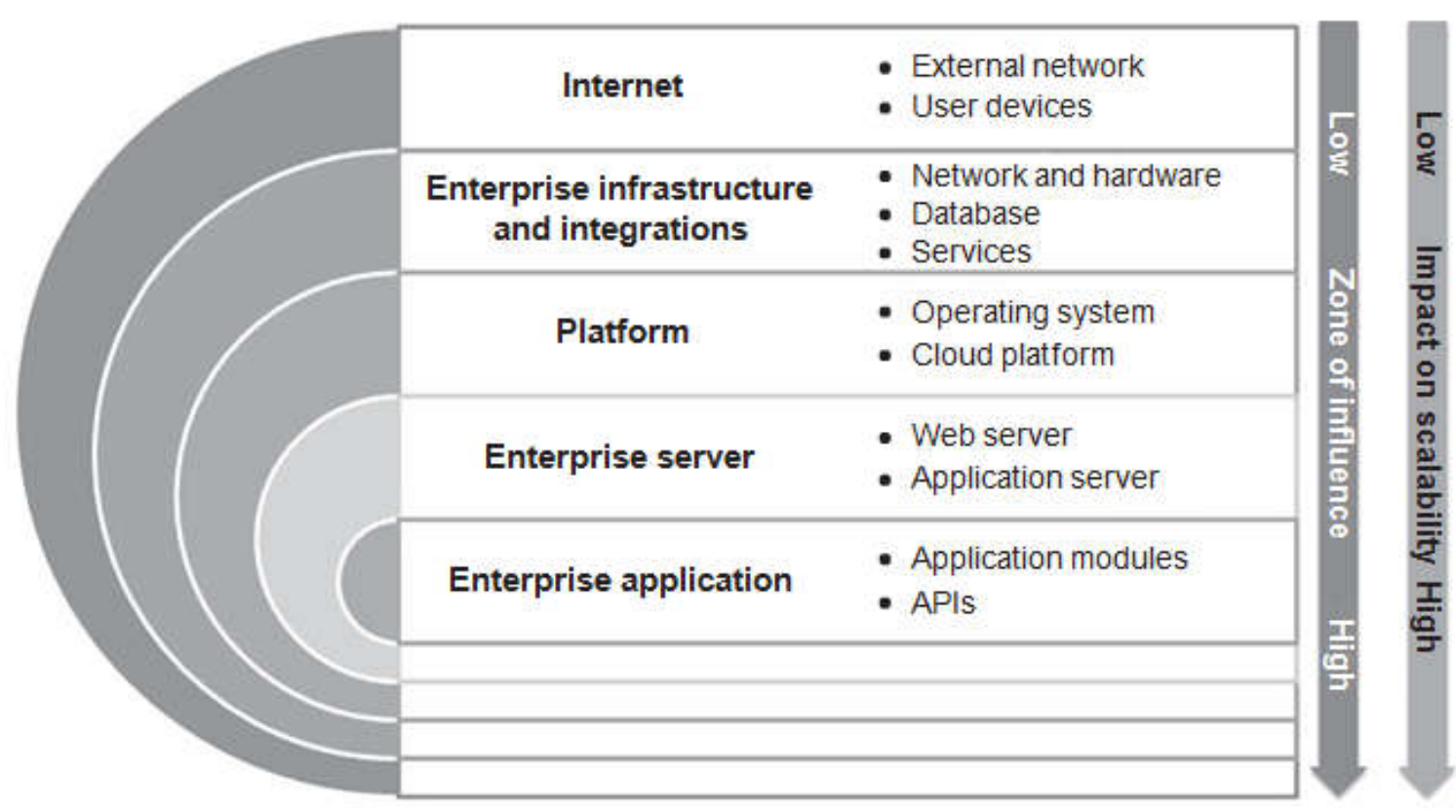

Figure 4: Layers of Scalability and the Impact (Shailesh, 2015)

In the online banking system, the layer of enterprise application is represented by core banking system. When talking about application system performance, one of the major parameter is application speed to response the request. Both server and enterprise applications are the main actors in generating response time (Techempower, 2016).

\subsection{Scalability - Vertical or Horizontal}

Open Banking models also need the elasticity. This is the degree to which a system can quickly adapt to workload changes by utilizing and upgrading resources in an on-demand manner. During the system application is running, if suddenly any additional workload system must be easy to scale up and if necessary to add the required resource.

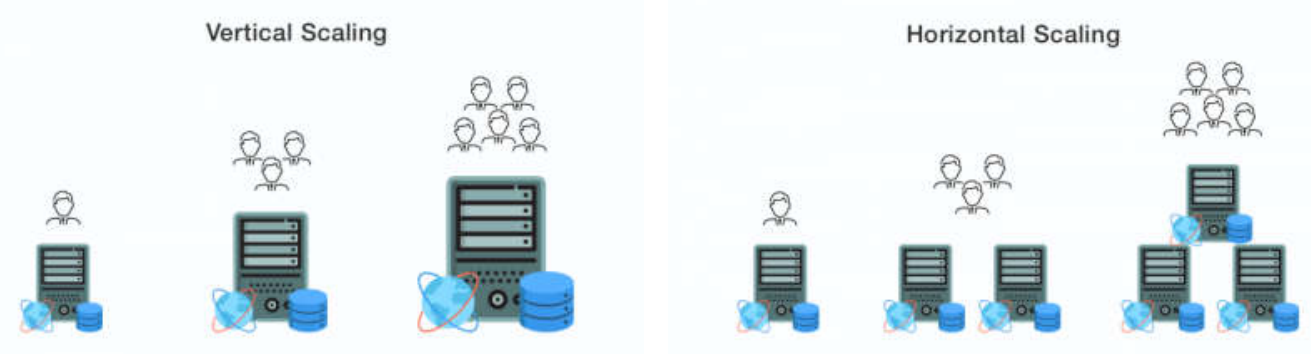

Figure 5: Vertical and horizontal Scalability

When there is an increase in transaction volume that cannot be handled by the existing specs server, it is necessary to increase the existing server capacity. Basically there are two types of scalability: vertical and horizontal. Vertical means with the existing box of server, we add the capacity by upgrading the resources of memory, processor, storage or others depend on the specific required to upgrade. And horizontal scaling is adding the capacity by adding the number of box server. The decision to choose either vertical or horizontal is depend on the related application capability to manage the scalability. Especially for vertical, it also depends on the server technology capabilities used, can it be upgraded up to the desired capacity. 
The horizontal scaling now is more popular in the open banking architecture because of several things such as below:

- It's elastic.

- It is dynamic. The existing resources can be kept still as it is and online during the additional the new server. It doesn't have the negative (risk) implication to the existing or previous server.

\subsection{Scalability Testing Methodology}

Figure-7 is the new testing methodology for this core banking system scalability review testing. It was modified and adjusted from the previous references of the PSR (Performance, Scalability and Reliability) testing methodology.

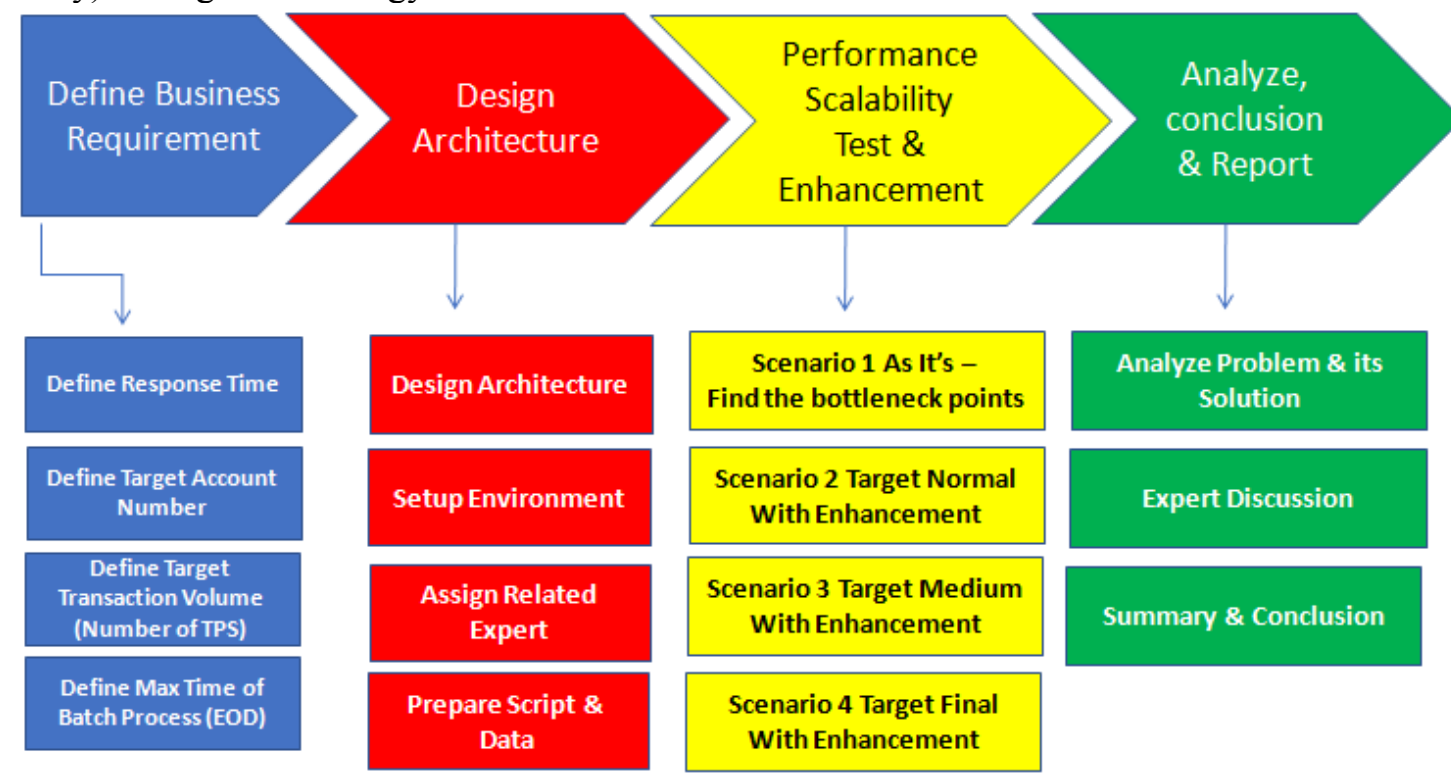

Figure 6: Scalability Performance Testing Methodology

\subsubsection{Define Business Requirement}

Bank could be lower their competitiveness if they slowly adopt the Digital Banking Technology, but it could worsen their financial performance if they adopt it aggressively (Rosnita, 2018). Thus the business team must decide to what number the system must be scalable in accordance with the business value and targeted growth. These numbers will be a reference for the IT team in designing and preparing the required system scalability.

To ensure the scalability of traditional core banking system, there are parameters should be provided by business team: Expected response time (seconds), Target account number, Target online transaction Volume, Maximum time duration of batch process (EOD and SOD)

\subsubsection{Design Architecture}

The business number targeted by bank will be main reference to design the IT System Architecture. In this stage, all related components must be prepared and estimated able to cover the business number and its growth (Shailesh, 2015). As this works focus on traditional core banking system scalability, the preparation components is as follows: Design Architecture, Setup Environment, Assign Related expert, Prepare the Data and Test Script.

\subsubsection{Performance Scalability Test and Enhancement}

It's identified that for the end to end enterprise system architecture, application layer is the main component of which we have the control, and also giving a maximum impact on scalability (Shailesh, 2015). At the application layers, the scalability is contributed by: software, process, and hardware. The challenges on software include potential issues and bottleneck in application code. And the hardware 
challenge includes the server and infrastructure components such as memory, CPU, Disk capacity and network.

\subsubsection{Analyze, Conclusion and Report}

All data and results in this scalability testing are collected and documented. The experts then discussed together including with other related parties and business or user team. Conclusions and suggestions must be made in accordance with the direction of strategy scalability targeted by the company (bank).

\section{Results and Discussion}

The research carried out was by conducting scalability testing of core banking system based on the methodology that has been made (as per explained in the previous chapter). The first step is defining the target business volume. From the current volume, it's targeted the aggressive growth at year-5 and year10 (as per stated at table-1). The second stage was testing environment preparation before doing the detail activities of scalability testing.

At the first stage of scalability testing, the focus was finding scalability bottleneck of the current traditional core banking system. All expertises were involved in this activity. Every bottleneck found during test should be solved (application customization or hardware adjustment) and then did the repeated test. This is done back and forth and repeatedly until getting the optimal results. Figure- 8 is sample profile application in one step of testing. It explains which program should be enhanced as it consumed high CPU and I/O.

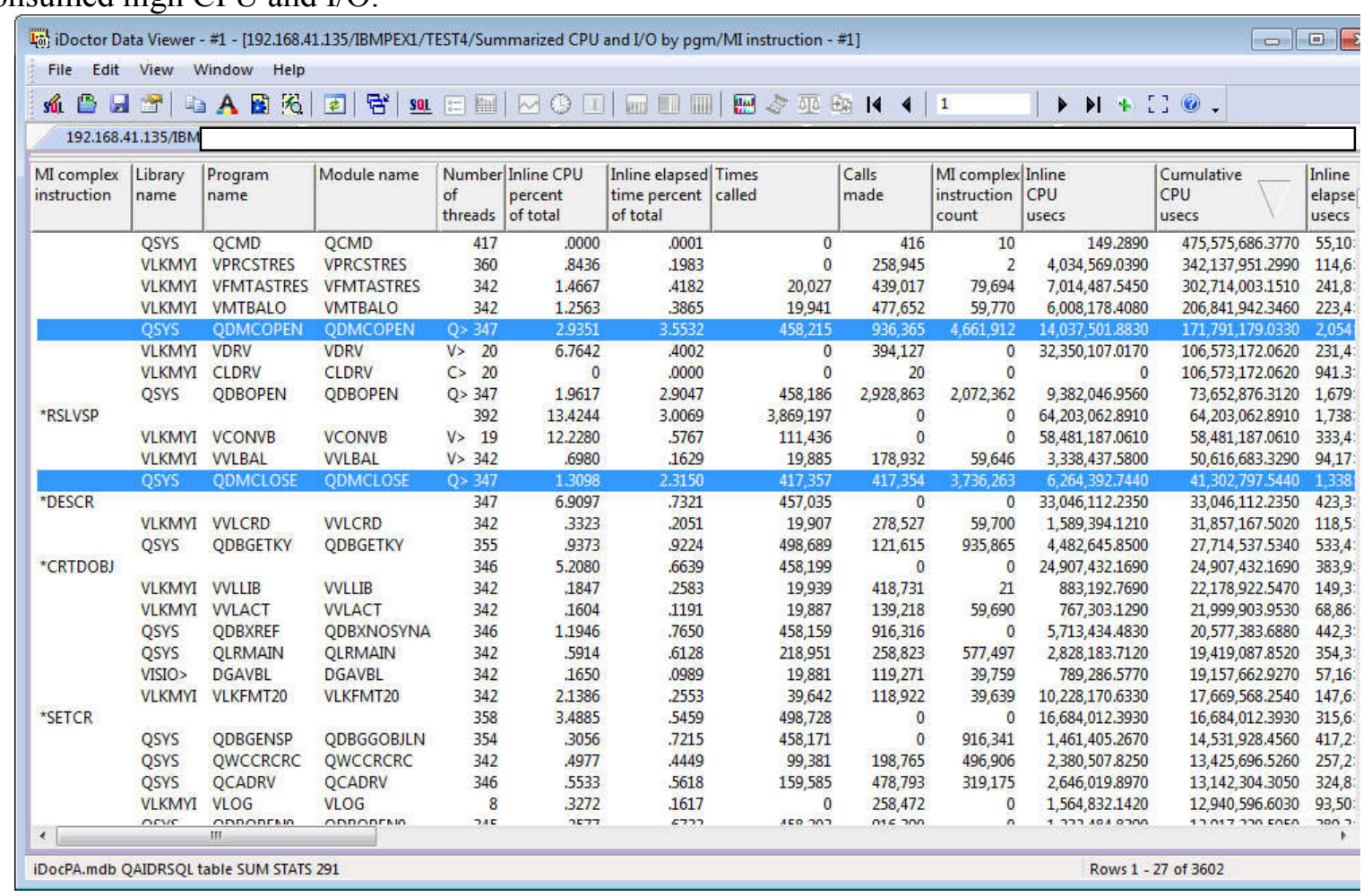

Figure-7: I/O and CPU consumption of Programs at Core Banking system

There were many major customization done at core banking application, and also several adjustment and server setting. It's including utilize SSD disk technology that's resulted 3 times speed performance of the system.

Table-1 explained the target business volume and the detail core banking system scalability testing result. 
Table-1: Core Banking System Scalability Testing - Target Business and Result

\begin{tabular}{|c|c|c|c|c|c|}
\hline \multirow{2}{*}{ Scenario } & \multicolumn{2}{|c|}{ Target Business } & \multicolumn{2}{c|}{ Achievement } & Server Spec \\
\cline { 2 - 6 } & \# Account & TPS & $\begin{array}{c}\text { Online Transaction } \\
\text { Response time }\end{array}$ & $\begin{array}{c}\text { Batch duration for } \\
\text { End Of Day Process }\end{array}$ & Power 870 \\
\hline $\begin{array}{c}\text { Volume-1 } \\
\text { (Year-2) }\end{array}$ & $10 \mathrm{M}$ & 5,600 & $<200$ milliseconds & 56 minutes & $\begin{array}{c}4 \text {-cores, } \\
\text { Memory 64GB, } \\
\text { SSD 24x387 GB }\end{array}$ \\
\hline $\begin{array}{c}\text { Volume-2 } \\
\text { (Year-5) }\end{array}$ & $17 \mathrm{M}$ & 8,600 & $<200$ milliseconds & 1 hour 25 minutes & $\begin{array}{c}\text { Memory } 64 \text {-cores, } \\
\text { SSD 24x387 GB }\end{array}$ \\
\hline $\begin{array}{c}\text { Volume-3 } \\
\text { (Year-10) }\end{array}$ & $50 \mathrm{M}$ & 13,000 & $<200$ milliseconds & 1 hour 31 minutes & $\begin{array}{c}\text { Memory 128GB, } \\
\text { SSD 24x387 GB }\end{array}$ \\
\hline
\end{tabular}

\section{Conclusion}

Regarding to implementation of open banking models, bank has to review their core banking system scalability. It's reminded by MIT (MIT Technology Review Insight 2018), that bank with traditional core banking system platform might be has more challenges in this scalability. This paper has concluded that:

1. Traditional core banking system running on power platform can be scalable to support open banking strategy. But it is vertical scalability and need enhancement in the core banking application.

2. The detail enhancement of core banking application may vary and differ from one bank to another. It can be identified after scalability performance testing is conducted.

3. The response time of core banking to support online banking can be targeted not more than 250 milliseconds.

4. The scaling of power server depends on the target business volume. The upgrading server specification especially is on number of CPU, memory and disk technology and capacity.

\section{References}

Accenture. Exploiting Inbound and Outbound Trade Opportunities, the Brave new World of Open Banking, 2018

Akamai. Akamai Reveals 2 Seconds as the New Threshold of Acceptability for eCommerce Web Page Response Times. Available at https:/www.akamai.com/us/en/about/news/press/2009press/akamai-reveals-2-seconds-as-the-new-threshold-of-acceptability-for-ecommerce-webpage-response-times.jsp, 2009

Akshay Kumar,Magapu and Nilhil Yralagadda: Performance, Scalability, and Reliability (PSR) challenges, metrics and tools for web testing, Faculty of Computing Blekinge Institute of Technology SE-371 79, Karlskrona, Sweden, 2016

Deloitte Digital: Open Banking, What Does The Future Hold? - April 2017

Fida Hussain Chandio, Zahir Irani, Akram M. Zeki, Asadullah Shah, and Sayed Chattan Shah (2017). Online Banking Information Systems Acceptance: An Empirical Examination of System Characteristics and Web Security. Informations System Management 2017, VOL. 34, NO. 1, $50-64$

$\mathrm{Hu}, \mathrm{Y}$., Liao, P. Finding critical criteria of evaluating electronic service quality of Internet banking using fuzzy multiple-criteria decision making. Applied Soft Computing 11, 3764-3770, 2011

IBM Corporation: IBM i on Power - Performance FAQ, IBM Power System Performance Book, 2019

MIT Technology Review Insight: Open Banking - The Race to deliver banking as service, 2018

Mohsen Mazaheri Asad, Najma Sadat Mohajerani, Mohammad Nourseresh: Prioritizing Factors Affecting Customer Satisfaction in the Internet Banking System Based on Cause and Effect Relationships. . 1st International Conference on Applied Economics and Business, ICAEB 2015 
Picarlo Gera: Managing digital disruption in Banking, https://www.accenture.com/hu-en/insightperspectives-banking-digital-strategy-drives-new-era - 2019

Ping Li, Dong Shi, and Jianping Li. Performance test and bottle analysis based on scientific research management platform. 2013 10th International Computer Conference on Wavelet Active Media Technology and Information Processing (ICCWAMTIP), pages 218-221, 2013

Rosnita Wirdiyanti: Digital Banking Technology Adoption and Bank Efficiency: The Indonesian Case, Dec 2018

Shailesh Kumar Shivakumar: Architecting High Performing, Scalable and Available Enterprise Web Applications, Elsevier Book - 2015

Techempower: think about performance before building a web application, https://www.techempower.com/blog/2016/02/10/think-about-performance-before-building-aweb-application/, 2016

Tiantian Gao, Yujia Ge, Gongxin Wu and Jinlong Ni, "A Reactivity Based Framework of Automated Performance Testing For Web Applications" $9^{\text {th }}$ International Symposium on Distributed Computing and Application to Business, Engineering and Science.

Varda Sardana and Shubham Singhania: Digital technology in the realm of banking: A review of literature, International Journal of Research in Finance and Management 2018; 1(2): 28-32

Yogita M. Rasal, Sangeeta Nagpure: Web Application Performance Testing Using Reactive Based Framework, International Journal of Research in Computer and Communication Technology, Vol 4,Issue 2 ,February -2015 